\section{JUVENTUDES Y POLÍTICAS PÚBLICAS DE INSERCIÓN LABORAL. SENTIDOS CONSTRUIDOS POR EMPRESARIOS LOCALES DEL GRAN RESISTENCIA}

\author{
YOUTH AND LABOR INSERTION POLICIES. \\ SENSES BUILT BY LOCAL BUSINESS PEOPLE FROM \\ GREAT RESISTENCIA
}

\section{Daiana G. I Cardozo | Pablo Andrés Barbetti}

\section{RESUMEN}

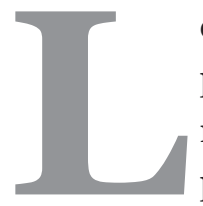

os procesos de inserción laboral en las juventudes pueden comprenderse como construcciones sociales en la que participan muchos actores, con intereses diversos. En este artículo ${ }^{1}$ específicamente nos centramos en la descripción de los sentidos construidos por los empresarios del aglomerado urbano Gran Resistencia, sobre los jóvenes y las políticas públicas de formación e inserción laboral. Luego de realizar una discusión derivada de la revisión bibliográfica sobre la temática, avanzamos en el análisis del contenido de entrevistas semiestructuras efectuadas a actores locales, con los perfiles antes mencionados. Los datos relevados muestran que no hay una orientación o tipo de discurso único en este colectivo, sino que es más bien diversificado. Se presentan lecturas diferenciadas con respecto a las intervenciones estatales orientadas a la promoción del empleo. En cuanto a las juventudes, tampoco hay un discurso unificado, se presentan referencias tanto positivas como negativas, las últimas con una fuerte carga semántica que nos permite inferir ciertas visiones estereotipadas por parte de algunos actores.

Palabras clave: empresarios, juventudes, formación para el trabajo.

\section{ABSTRACT}

The processes of labor insertion in youth can be understood as social constructions in which many actors participate, with diverse interests. In this article we specifically focus on the description of the senses built by the entrepreneurs of the Gran Resistencia urban agglomerate, about young people

\footnotetext{
${ }^{1}$ Esta comunicación, se enmarca en un proyecto de investigación acreditado en la Secretaría General de Ciencia y Técnica de la Universidad del Nordeste (PI 18H001) y en un sub-proyecto realizado en el marco de una beca investigación otorgada por este mismo organismo.
}

Daiana G. I Cardozo cardozodaiana7o@gmail.com Instituto de Investigaciones Educativas

Facultad de Humanidades

Pablo Andrés Barbetti pablobarbetti@hotmail.com

Instituto de Investigaciones Educativas Facultad de Humanidades

Departamento de Ciencias Sociales Facultad de Ciencias Económicas

Universidad Nacional del Nordeste ARGENTINA

\section{COMO CITAR ESTE ARTÍCULO}

Cardozo, D. G. I. y Barbetti P. A. (2019). Juventudes y Políticas Públicas de inserción laboral. Sentidos construidos por empresarios locales del Gran Resistencia. Revista de la Facultad de Ciencias Económicas, 23( 2), 71 - 89. http://dx.doi.org/10.30972/rfce.2324019
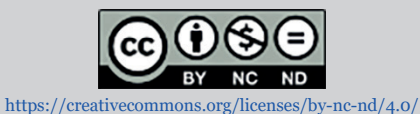
Revista de la Facultad de Ciencias Económicas ISSN 1668-6357 (formato impreso) ISSN 1668-6365 (formato digital) por Facultad de Ciencias Económicas Universidad Nacional del Nordeste (UNNE) Argentina se distribuye bajo una Licencia Creative Commons Atribución - No Comercial - Sin Obra Derivada 4.0 Internacional. 
and public policies for training and job placement. After conducting a discussion derived from the bibliographic review on the subject, we moveforward in theanalysis of the content of semi-structured interviews with local actors, with the aforementioned profiles. The data shown show that there is no single orientation or type of discourse in this group, but rather is diversified. Differentiated readings are presented regarding state interventions aimed at promoting employment. As for the youth, there is also no unified discourse, both positive and negative references are presented, the latter with a strong semantic load that allows us to infer certain stereotyped visions by some actors.

Keywords: businessmen, youth, job training .

\section{INTRODUCCIÓN}

Como lo señala Ibarrola (2016) las relaciones entre educación y trabajo son sobre todo complejas y plurales, siendo difícil abordar dicha complejidad tomando solo variables de formación y de tipo económica sin sesgar el análisis, dado que cada una de estas esferas está atravesada por diferentes desigualdades y constituida por juegos de fuerza entre múltiples actores (Ibarrola 2016). En el mismo sentido, entendemos a los procesos de inserción laboral de las juventudes como construcciones sociales en la que participan muchos actores, con intereses y capitales diversos (Jacinto, 2008). Asimismo, más allá de las lógicas universales, los caminos de los jóvenes en el mercado de trabajo se inscriben en contextos nacionales cuya estructuración y regulación van a diferir (Verdier y Vultur, 2018). Pensamos a los empresarios locales como actores sociales que, si bien sus acciones poseen límites originados en los condicionamientos estructurales, tienen la posibilidad de desempeñar sus papeles en relación con sus interpretaciones del contexto en el que se mueven, especialmente con respecto a las expectativas sobre la acción de los otros protagonistas del sistema social al que pertenecen (Alonso, 2004).

En este marco, el objetivo de este trabajo es identificar y describir algunos de los sentidos construidos por los empresarios del Gran Resistencia, sobre los jóvenes y las políticas públicas de formación e inserción laboral y asimismo, sus posicionamientos como actores en relación a los procesos de inserción laboral en las juventudes.

Cuando hablamos de sentidos hacemos referencia al contenido propio de un texto, lo que expresa más allá de la designación y el significado, es decir, la intención, la finalidad, las implicaciones en los discursos (Coseriu, 1981). Indagar en estos discursos adquiere relevancia, considerando que los actores empresariales se vuelven determinantes, dada la influencia de los mismos desde sus esferas de acción, en los procesos de socialización en el trabajo y en reconfiguración de las políticas públicas referidas a la formación/inserción laboral de las juventudes. 
El texto que presentamos se organiza en cuatro secciones: en la primera presentamos el marco teórico-conceptual que orientó el estudio, en la segunda realizamos una caracterización del contexto donde se realizó el estudio, del diseño metodológico utilizado así como de los empresarios entrevistados. En la tercera presentamos el análisis de los sentidos construidos por los empresarios y, por último, las reflexiones finales derivada de los principales hallazgos expuestos en el trabajo.

\section{MARCO DE LA INVESTIGACIÓN}

La empresa y el actor empresario han sido punto de análisis desde distintas perspectivas en búsqueda de una comprensión y definición de los mismos. En este apartado nos detendremos, muy brevemente, en algunas de estas construcciones teórico-conceptuales.

Las teorías de la administración particularmente con más énfasis entrado el siglo XX, han estudiado en sus inicios a la empresa desde una orientación mayormente economicista, ligada a los procesos político-administrativos que en la misma se suceden. Bueno Campos (2007) define la empresa como "la unidad económica que combina los distintos factores productivos, ordenados según una determinada estructura organizativa, y dirigidos sobre la base de cierta relación de propiedad y control, con el ánimo de alcanzar unos objetivos, entre los que destaca el beneficio empresarial”. Desde estas perspectivas, se reconoce en parte también que la empresa tiene además una importante dimensión social, pues es una fuente importante de creación de empleo y de generación de riqueza en la sociedad.

Desde el punto de vista jurídico, Piris y Glibota (2015) aluden que la empresa como figura jurídica resulta problemáticamente conceptualizable. Citando a Etcheverry (2005) plantean que el término es del siglo XIX pero el concepto es del siglo XX, y que no existe una definición legal que la englobe o pueda englobarla por su complejidad. Lo último, presenta la dificultad de aprehender una realidad tan amplia y dinámica en un concepto estático.

Referenciados en la sociología económica, Dossi y Dissin (2011) presentan la noción de acción empresarial organizada, como herramienta analítica de las acciones colectivas del actor empresario. Dichas acciones se producen al interior de las organizaciones empresariales "se presentan con el objetivo de amalgamar posiciones disímiles para luego expresarlas mediante la acción política colectiva, en forma consensuada y homogénea, en el plano político-institucional" (Dossi y Lissin, 2011 p.416). Desde esta perspectiva, que es la que aporta de manera más directa a este estudio, el empresariado no se presenta como un sector uniforme sino más bien compuesto por diferencias constitutivas de su heterogeneidad, que no obstante pueden llegar a converger en acciones sociales y políticas comunes. 


\subsection{Formación para el trabajo y políticas públicas de inclusión socio laboral orientadas a las juventudes}

Concebimos a la formación para el trabajo ${ }^{2}$ como un campo complejo y heterogéneo de acciones públicas y privadas, a menudo en alianza, con intereses a veces complementarios, frecuentemente contradictorios. Asimismo, desde el punto de vista de sus formas institucionales, es probablemente la parte más heterogénea del sistema de educación y formación de los países, con estructuras y ofertas que muchas veces funcionan en paralelo (CEDEFOP, 2017 citado en Jacinto, 2019).

En la actualidad, la formación para el trabajo de jóvenes enfrenta múltiples desafíos, entre ellos, el deterioro del mundo del trabajo (desempleo, precarización) y el aumento en los requerimientos de competencias básicas y transversales para la vida y para cualquier empleo. $\mathrm{Al}$ mismo tiempo, ese piso básico se contrasta con la evidencia creciente de una polarización de las calificaciones demandadas. El empleo y la educación, como grandes motores de la movilidad social del siglo XX, se han debilitado (Jacinto y Milenaar, 2012). Asimismo, los cambios que se producen en el entorno empresarial, caracterizados por la globalización de la economía y la continua introducción de las nuevas tecnologías en los procesos de producción y administración en las organizaciones, han provocado a su vez, cambios en las estructuras al interior de las mismas, existiendo la tendencia al aplanamiento de estructuras y a la constante evolución de los puestos de trabajo, lo cual hace difícil mantener la estabilidad de los mismos (Valencia, 2005). En este proceso de cambio, el propio paradigma de la formación fue revisado, nuevos actores institucionales ingresaron al campo de la formación y se diseñaron programas específicos. Sin embargo, solamente los programas públicos de capacitación e inserción laboral para jóvenes han logrado una cobertura significativa (Vera, 2009).

Siguiendo los aportes de Claudia Jacinto (2008), podemos organizar los dispositivos orientados a acompañar los procesos de inserción y formación de los jóvenes en dos grandes periodos de tiempo: por un lado el que se desarrolló durante la década del 90 en Latinoamérica, y; por otro lado, los que surgen partir del año 2000. Los años noventa se caracterizaron por el desarrollo de programas focalizados de formación, de acciones a corto plazo, donde no existía una articulación entre la formación profesional y las propuestas de educación formal. A partir de los años 2000, se produjo una reformulación en algunas de las iniciativas de este tipo, que incluyen cosmovisiones diferentes acerca del papel del Estado, de la institucionalidad de la formación profesional, así como de los diagnósticos de los que parten en relación con el modo en que problematizan la cuestión del empleo juvenil. Se pasa, entonces, desde una perspectiva centrada en "las necesidades de capacitación" (de los años 90) a otra que enfatiza "las necesidades de orientación”. Se advierte también en algunos programas una cierta reorientación basada en la acumulación de aprendizajes en función de los resultados de las acciones y las adecuaciones

${ }^{2}$ Entendemos a la formación para el trabajo como aquella que tiene por objetivo proveer a las personas de conocimientos, know-how, habilidades y / o competencias requeridas en ocupaciones particulares o más ampliamente en el mercado laboral" (CEDEFOP, 2014, citado en Jacinto 2019). 
a nuevos contextos y actores. Entre ellos, al menos desde los diseños de los programas aparece el actor empresarial con más protagonismo en estos procesos. Aun así, los cambios de enfoques no son homogéneos, conviven distintos dispositivos y las conceptualizaciones acerca de ejes claves remiten a diversas perspectivas ideológicas y socio-culturales. En relación a las necesidades de orientación, se señala que en parte las dificultades de acceso de los jóvenes vulnerables a empleos de calidad se relacionan con que los mismos no siempre manejan códigos, roles y rutinas habituales del ámbito laboral (Jacinto, 2010). Consecuentemente, los dispositivos estatales intentan actuar como intermediarios en el acceso al empleo, no sólo brindando competencias específicas sino también, aportando saberes para la construcción de un proyecto ocupacional propio. Esto conlleva que la inclusión social y laboral se vincule al trabajo con la esfera subjetiva de los jóvenes (su autoestima, sus actitudes, motivaciones, expectativas).

A nivel local, ya desde hace algunos años se vienen implementando dispositivos estatales que cumplen esta función de intermediación y acercamiento entre los jóvenes y las empresas (Barbetti et al., 2017). Algunas de estas iniciativas apuntaron a afianzar "la construcción de estrategias colaborativas y de diseñar herramientas que se adapten a las dinámicas de los espacios locales, promoviendo canales de coordinación entre los diferentes niveles de la administración pública y articulación con distintos actores (privados, sociales, académicos, etc.)"(Pozzer, 2018, p.84).

\subsection{La construcción de las juventudes}

Los estudios recientes sobre juventud convergen en señalar que es necesario pensar a las mismas de un modo plural, de manera relacional, reconociendo como ciertas dimensiones de clase, género, raza y etnicidad, entre otras se traducen en desiguales maneras de ser joven -de construirse y ser construido como tales- (Segura, 2017). De lo que se trata, entonces, es en pensar en las múltiples formas de ser joven en el marco de la intensa heterogeneidad económica, social y cultural (Margulis y Urresti, 1998).

Cada sociedad define a la juventud a partir de sus propios parámetros culturales, sociales, políticos y económicos, por lo que no hay una definición única. En este sentido, los discursos sociales y en particular los académicos, fueron construyendo, reproduciendo e incluso naturalizando determinados rasgos que encasillan a los jóvenes en categorías clasificatorias, descriptivas o interpretativas. Las categorías que se construyen en torno a las juventudes no son neutras, ni esencialistas sino productivas, y es a través de determinados discursos y sus manifestaciones que las representaciones sobre los y las jóvenes cobran forma y vigor (Palazzo, 2014).

En su trabajo "la construcción social de las juventudes" Alpizar y Bernal (2003) presentan las principales construcciones teóricas que desde distintas disciplinas y momentos en la 
historia se aproximaron a la juventud, intentando hegemonizar las discusiones y abordajes sobre las mismas. Así, la autora muestra como la juventud fue definida: como una etapa del desarrollo psicobiológico humano, como un momento clave para la integración social, como un dato sociodemográfico, como un agente de cambio, como un problema de desarrollo social, como generación y, más recientemente como una construcción sociocultural.

La mayoría de estos estudios realizados desde la última perspectiva (como construcción sociocultural) han sido desarrollados fundamentalmente desde el campo de la antropología y la sociología, resaltando la diversidad de formas de expresión de lo juvenil (culturas juveniles) y subrayando la diversidad de lo juvenil (identidades juveniles). En esta misma línea Duarte (2012) menciona el carácter relacional que asume la construcción de las juventudes y, partiendo de la noción de clases de edad, indica que las sociedades occidentales se configuran como adultocéntricas:

Podemos explicitar entonces que nos posicionamos desde la consideración del carácter de construcción social, ya no sólo de lo juvenil, sino de las diversas clases de edad - niñez, adultez, adultez mayor-, para desde ahí reflexionar en torno a una característica que posee nuestra sociedad occidental y es su condición adultocéntrica. Ella remite a unas relaciones de dominio entre estas clases de edad -y lo que a cada una se le asigna como expectativa social-, que se han venido gestando a través de la historia, con raíces, mutaciones y actualizaciones económicas, culturales y políticas, y que se han instalado en los imaginarios sociales, incidiendo en su reproducción material y simbólica (Duarte, 2012, p.103).

La idea de adultocentrismo refiere, entonces, a la existencia de un sistema de dominio que, a su vez, puede conjugarse con otros sistemas de dominio como el patriarcado, el capitalismo, la segregación territorial. La adultez como edad social, permite el control y la subordinación sobre las personas consideradas en la minoridad. La definición se hace por diferencia de grado en relación al parámetro elegido, lo que lleva a establecer características desde la falta, las ausencias y la negación, y son atribuidas al sujeto joven como parte esencial de su ser (Chaves, 2005).

\section{CARACTERIZACION DEL CONTEXTO, DESCRIPCION DE ASPECTOS METODOLOGICOS Y DE LOS EMPRESARIOS ENTREVISTADOS}

El aglomerado urbano Gran Resistencia ${ }^{3}$ se ubica en la Provincia del Chaco, que integra la Región Nordeste de Argentina (NEA). Dado el devenir de los procesos sociohistóricos que dan lugar a la configuración de la estructura socioeconómica del país, esta región ha tendido a caracterizarse por cierto grado de postergación de sus estructuras socioculturales, productivas 
y laborales en comparación con otras regiones, especialmente la región centro, lo que explica el desarrollo de algunos sectores por sobre otros (Foio y Pérez Rubio, 2009).

Por su parte, la provincia del Chaco, en particular posee un perfil productivo históricamente muy sesgado a los productos primarios (algodón en sus orígenes, arroz y soja en la actualidad). Respecto a la generación de empresas predominan las del sector comercio y servicios por encima de las pertenecientes al sector primario y de la industria manufacturera. Con respecto a la última, la estructura industrial posee un alto nivel de concentración en torno a tres ramas productivas principales: alimentos y bebidas, sustancias químicas y productos textiles (Schorr et al., 2016). Asimismo en lo que se refiere a la creación de empleo privado formal, también los sectores de comercio y servicios son los que más ocupación generan. Un dato significativo, es la existencia de un grupo conformado por 7 (siete) empresas de Call Centers, instalado hace pocos años en la provincia, que genera más de 5.000 puestos de trabajo, en su mayoría orientados a jóvenes. ${ }^{4}$

$\mathrm{Al}$ momento de realizar el trabajo de campo (entre los meses de mayo a noviembre del año 2018) el empresariado local se encontraba atravesando un momento de crisis y recesión económica, vinculada a los efectos de las políticas macroeconómicas nacionales y sus efectos negativos en las pequeñas y medianas empresas (PyMES). ${ }^{5}$

Respecto al diseño metodológico, considerando los objetivos iniciales propuestos, optamos por un abordaje de tipo cualitativo. Los datos empíricos fueron construidos a partir de la realización de entrevistas semiestructuradas efectuadas a empresarios del aglomerado urbano antes mencionado. A tal efecto se construyó una muestra intencional y las unidades de análisis fueron seleccionadas considerando los siguientes criterios: la dimensión de las empresas (en cuanto a la cantidad de trabajadores), el sector o rama de actividad y el origen del capital (de capitales locales, nacionales o transnacionales).

Puntualmente se realizaron un total de 25 (veinticinco) entrevistas a empresarios de los siguientes sectores de la construcción y relacionados; software y servicios informativos; comercio y servicios (gastronomía, indumentaria, insumos, electrónica, servicios profesionales) y producción (alimentos, calzados). Respecto a sus posiciones en su mayoría, los casos comprenden a empresarios propietarios o con la figura de socio-gerente, que se desempeñan en micro, pequeñas y medianas de capital local, incluyendo también en menor medida, actores cumpliendo funciones de gerencia en empresas grandes, de capital nacional e internacional. Varios de éstos presidían o ejercían cargos en cámaras empresariales locales, regionales o nacionales.

Si tenemos en cuenta la composición etaria de los consultados, podemos distinguir 3 (tres) grupos: adultos jóvenes entre 24 y 35, en la adultez media entre 40 y 60 años y en menor medida adultos mayores entre 60 y 75 años. En proporción más varones que mujeres. En

\footnotetext{
${ }^{4}$ Este proceso fue acompañado y promovido desde el Estado Provincial con la aprobación de la Ley № 6209 que exime a las empresas del pago de los impuestos a los ingresos brutos y sellos en un $100 \%$ durante los primeros cuatro años e incluye otros incentivos tales como subsidios a la contratación, servicios de selección y capacitación de personal.

${ }^{5}$ En la provincia Chaco, en febrero de 2016 estaban registradas formalmente 9.310 empresas (entre los sectores: construcción, primerio, industria, servicios, energía y Call centers) para pasar a 8.901 en febrero de 2019, correspondiéndose lo anterior con la caída del empleo privado formal. Datos provistos por la Oficina de Relevamiento de Datos e Información. Ministerio de Industria Comercio y Servicios. Provincia del Chaco.
} 
cuanto al nivel de estudios alcanzados, la mayor parte cuenta con estudios de nivel superior completos, en curso o que debieron postergarse. Cabe resaltar además, que algunos de los entrevistados se desempeñan o se desempeñaron, como capacitadores o docentes en diferentes niveles del sistema educativo.

\section{LAS CONSTRUCCIONES DE SENTIDO DE LOS EMPRESARIOS ENTREVISTADOS}

\subsection{Sobre las Juventudes}

Podemos distinguir que, en los actores entrevistados, no existen discursos únicos sobre las juventudes, ni tampoco alusiones a un sólo tipo de joven. Aparecen en las emisiones atribuciones, características o rasgos de lo que podemos inferir posiciones más comprensivas donde se destacan sus potencialidades como grupo y sus aportes a las organizaciones empresariales. Por otra parte y en contraposición, surgen concepciones como altamente ideologizadas que tienden a cierta estereotipacion.

Se distingue una mirada adultocéntrica de la condición juvenil en gran parte de las referencias de los actores. Dicha mirada se cristaliza aun en empresarios jóvenes en términos de edad cronológica pero que asumen una clase edad (Duarte, 2012), una edad social, una posición en la estructura, mediada en este caso por la tenencia del capital. Se exaltan las carencias y desviaciones de las juventudes actuales muy marcadamente en algunos casos y en otros, como mencionamos precedentemente, posiciones más comprensivas de la condición juvenil pero desde la comparación autorreferencial y paternalista.

Algunas emisiones dan cuenta de una visión que valoriza las potencialidades de los jóvenes en términos de aprendizaje y comprensión de sus entornos: "Los chicos tienen una sed terrible de aprender, son muy sensibles, vienen con otra impronta" (E12)6. "Tienen la posibilidad de absorber conocimiento mucho más rápido, porque están estimulados desde chicos" (E19).

Además son mencionadas ciertas competencias que los jóvenes pueden poner en juego en los ámbitos laborales, e intereses y elecciones sobre los mismos. En sentido, se destacan fundamentalmente aquellas cualidades de los jóvenes que benefician a la productividad de las organizaciones (Margulis y Urresti, 2003): "Son proactivos si el ambiente de trabajo los motiva pueden pensar ideas y soluciones en pos de la organización, son creativos y para este rubro es muy necesario" (E8), "Son más sofisticados, menos rústicos y a mí en rubro me sirve"(E12), "los jóvenes aportan un montón de cosas (...) ideas nuevas, procesos nuevos, metodologías nuevas, miradas nuevas, concepciones nuevas que son útiles para probar, que pueden llegar a andar mal pero generan evolución adentro de la empresa" ( E23). 
Del mismo modo, aparecen referencias sobre las preferencias en cuanto a los ámbitos laborales, donde se resalta que como grupo que se inserta laboralmente, la colaboración, la sensación de bienestar y los tiempos de ocio se prefieran por sobre otras condiciones de trabajo (González, 2011):

"yo creo que los jóvenes cada vez valoran más cuestiones cualitativas de los entornos laborales, cada vez más, es decir, el clima laboral...trabajar en algo que le gusta, algo que se da mucho en el rubro tecnológico al haber tanta demanda pueden darse el lujo de elegir donde trabajar y en que trabajar, y eso se nota mucho y prácticamente uno no tiene trabajando a alguien, sobre todo si es joven, en una tecnología o en un proyecto que no es de su interés. Los jóvenes tienen cierta tendencia a elegir siempre los gustos y a priorizar los gustos por sobre las cuestiones cuantitativas, por ejemplo económicas" (E 6).

"el joven quiere hacer lo que le gusta, lo que ame y poder satisfacerse con el mismo trabajo" (E1O).

En el discurso de algunos empresarios, se distinguen determinadas clasificaciones generacionales basadas en estudios sobre Recursos Humanos, con impronta managerial o de las teorías de la administración, que se han sido divulgadas y utilizadas por los medios masivos de comunicación. Hay cierta apropiación de este tipo categorizaciones para interpretar a los jóvenes y en este sentido, se resalta la necesidad que no reforzar "barreras generacionales" que separen empleadores de los jóvenes que ingresan a las empresas (González, 2011):

"Perfil diferentes según las generaciones, otras características según la generación, no es lo mismo la generación $Y$, que la X ni los Baby Boomers, son chicos nuevos son diferentes, perfiles diferentes- el empleador tiene que capacitarse cambiar las expectativas" (E12).

Quienes sostienen estas consideraciones son empresarios que en algunos casos, tuvieron experiencias de haber utilizado políticas de promoción del empleo (sea de formación o de inserción), provenientes de rubros como la gastronomía, call centers y software y en cuyas empresas contienen mayormente a jóvenes trabajando actualmente. Varios de estos son adultos jóvenes, aunque en el caso de las empresas de call centers y software son empresarios mayores de 35 años. Estos últimos, son los que más énfasis hacen con respecto a las preferencias sobre las condiciones laborales que priorizan los jóvenes y las competencias que desarrollan. Cabe mencionar que a diferencia de los otros sectores, para ocupar los puestos básicos en estas organizaciones se necesitan mayor calificación. Es decir, los jóvenes que según los consultados priorizan condiciones más flexibles de trabajo por sobre lo contractual y el salario, son los que en general mayores niveles educativos alcanzan (con estudios universitarios en curso o completos).

Por otra parte, emisiones donde los rasgos y atribuciones en relación a las juventudes son claramente más negativas reconocemos que, siguiendo los aportes de Duarte (2012), estas referencias dan cuenta de características de las sociedades de tipo adultocéntrico, donde se construyen imaginarios que afectan directamente las relaciones y los procesos identitarios de 
los diversos sujetos sociales y las relaciones entre clases de edad se han planteado como relaciones de tensión y conflicto. Estos conflictos se construyen en torno al desencuentro entre las expectativas de los mundos adultos respecto de las y los jóvenes y de estos con respecto a su papel y las oportunidades sociales:

"Pero también se nota una gran ausencia en las expectativas de vida porque esta despreocupación, porque uno puede tener despreocupación por...no sería lo mismo que te hable en realidad, porque te hable de la familia...es como que no tienen en claro a donde quieren llegar, viven nomás y la vida les pasó a ser como algo provisorio, hoy hago algo provisoriamente mañana... no tienen un objetivo claro" (E7).

La cuestión de las diferencias generacionales es algo que se reitera, la juventud aparece definida como grupo que puede compararse con otras generaciones de otros tiempos históricos en términos de conflicto (Alpizar y Bernal, 2003). Esto da lugar a la conformación de estereotipos sobre la gente joven de determinada época, estereotipos que se convierten en estigmas. Esta estigmatización se da en mayor medida a partir de imágenes elaboradas desde las apariencias y las miradas preconcebidas sobre los y las jóvenes (Duarte, 2012).

"Pero ahora si estás esperando, sin estudio, sin capacitación, cuando llegue la oportunidad vas a decir mirá si yo hubiera estudiado hubiera estado bien, mejor. Eso es lo que yo veo en los jóvenes que pasaron una etapa de su vida medio especulando, especulando entrar en la política, es decir, ya no hay tanto sacrificio como era antes, bueno yo creo que después va a volver a mejorar. Antes era todo sacrificio, ahora te dicen: vos sabes no me gusta este empleo voy a cambiar, voy a buscar, voy a esperar, todavía les gusta refugiarse con los padres entonces eso es lo que yo veo, hay excepciones eh, hay muchas excepciones eh, 'sí, sí, sí... hay muchas excepciones (E2).

Otra parte de los rasgos identificados en los discursos que responden también a una valoración negativa sobre los jóvenes, pueden interpretarse a partir de los planteos realizados por Chaves (2005) que indaga sobre las representaciones y discursos vigentes acerca de las y los jóvenes en la Argentina. La autora sostiene que la juventud está signada por "el gran no", es negada (modelo jurídico) o negativizada (modelo represivo), se le niega existencia como sujeto total (en transición, incompleto, ni niño ni adulto) o se negativizan sus prácticas (juventud problema, juventud gris, joven desviado, tribu juvenil, ser rebelde, delincuente, etc.). Así entre las emisiones aparecían descripciones tributarias de algunas de las siguientes representaciones:

a) Joven como ser no productivo económicamente: Dado que el tiempo de la productividad es el tiempo del trabajo, el joven es visto como un sujeto que está lleno de tiempo libre, es un ser "ocioso":

"Ahora el joven es más tranquilo, ve el futuro esperando y también medio tuvo la culpa la situación de este país, que hacía que le daba subsidio y yo no estoy de acuerdo con eso, si bien le ayudaba pero a las personas les tenes que ayudar a trabajar" (E2). 
Unos son muy buenos tienen iniciativa propia, son emprendedores pero hay otros que viven de las dadivas, los subsidios, están acostumbrados a eso, se suman dice que a la militancia y marchan, ni buscan trabajo" (E21).

b) Joven como ser desinteresado y/o sin deseo: algunos de los rasgos definidos por los actores consultados remiten a esta construcción. Aparece un señalamiento con mucha fuerza del no deseo o el no interés, pero que, a decir de Cháves (2005), está colocada y debería ser interpretado en que aquello que no se desea/interesa se vincula con lo que se les ofrece en determinados ámbitos específicos de socialización (la escuela, el trabajo, entre otros):

"son poco instruidos, sin compromisos, egoístas, apáticos (...) su vida es una pantalla"(E16).

c) Joven como ser incompleto: algunas descripciones también remiten a la construcción de un sujeto joven en transición y no productivo como un ser incompleto, desorientado, carente, al que le faltan cosas:

"Descompromiso, la gente es muy descomprometida en todos los aspectos de la vida, desde la pareja con la que inician una vida, desde su paternidad, en lo laboral lo mismo... se nota claramente que el joven está muy descomprometido en lo que hace.(...) el joven se malacostumbra muy rápido" ( $E 7)$.

d) Joven como ser desviado: dado que es un ser incompleto, no productivo e inseguro de sí mismo, el joven tiende a "desviarse del camino", desviarse de la norma, dado que sus objetivos no son claros:

"Por otro lado la falta de educación, se han perdido muchos valores, el valor de la familia, el valor de la...es como que va, va perdiendo peso no? En esto de la evolución de la transición, no sé si esto está mal o no, no sé si está mal o no digamos , no sé si es algo que yo podría por decirlo así juzgarlo, yo te voy describiendo rasgos que veo" (E17).

"Es muy raro, muy contadito el joven que tiene una visión de futuro, una visión de progresar, de aprender" (E13).

Los empresarios en cuyos discursos priman estas atribuciones de sentido con respecto a los jóvenes tuvieron, en algunos casos, experiencias de trabajo con los mismos que consideraron negativas. También personas que cumplen o cumplieron roles docentes. En cuanto a rango de edad son los mayores de 35 años los que acentúan más este tipo de discurso pero apare también en empresarios más jóvenes.

Podemos decir que estas valoraciones negativas hacia las juventudes pueden asociarse en parte, a la interpretación que estos actores hacen sobre los cambios sociales y cierto anclaje de los mismos a una "ética del trabajo". Cuarta (2018) señala que, en la esfera de lo simbólico, la ética del trabajo "se vincularía con fines trascendentes asociados a la ganancia del cielo, la responsabilidad histórica del progreso y el valor moral de participar en la riqueza de las naciones como una manera efectiva de integrarse al todo social" (p.142). La estereotipacion alrededor de los y las jovenes se construye cuando se percibe que estos no responden a la "cultura del trabajo" a la "ética del trabajo" tal como es concebida por los adultos. Las nuevas generaciones se 
vinculan de maneras diferentes con el trabajo y aparecen, en contraposición, algunos aspectos de la llamada "ética del consumo" donde, "el trabajo es despojado de su carácter "autotélico", es decir, ya no es un telos en sí mismo, ya no es "fin en sí". La eficacia simbólica se traslada entonces de la esfera de la producción a la del consumo” (Cuarta, 2008, p.148).

\subsection{Acerca de la formación para el trabajo y las políticas públicas de inserción laboral}

Se suele considerar al empresariado como un bloque homogéneo pero nada más característico que la heterogeneidad e diversidad, que en estos actores se denota no sólo en aspectos económicos, sino también en el fraccionamiento y la diversidad de pertenencias políticas, de trayectorias y orígenes que, a su vez, se manifiestan en la variedad de acciones que llevan adelante (Dossi y Lissin, 2011). A pesar de diferenciaciones, pueden llegar a converger en demandas comunes y acciones colectivas hacia los Estados.

Nos parece necesario comprender al Estado "como un constructo complejo, sabemos que está atravesado por diversas miradas, intereses y posiciones ideológicas” (Chorny, 2016, p.1) Lo anterior, teniendo en cuenta que los discursos de los actores consultados denotan lecturas diferenciadas sobre la acción estatal y sus instituciones. En este sentido, en algunas referencias se infiere la idea de Estado como un organismo que disputa recursos humanos y ganancias a las empresas:

"El Estado no va a la empresa (...) vive de la empresa" (E15). "El Estado es el principal socio de las empresas (E11).

En cuanto a las políticas de promoción del empleo destinadas a las juventudes, estas líneas se configuran como otro tipo de relación y responsabilidades que establecen con los Estados y sus agentes. Esto en cuanto al tipo de vinculación que establecen con los organismos y sus funcionarios, en marco de un escenario sociopolítico, económico determinado, podemos pensarlas como un tipo de acción empresarial de tipo político (Dossi y Lissin, 2011). Lo anterior, se puede distinguir más puntualmente en las emisiones de empresarios que asumen cargos dirigenciales o tienen responsabilidades en organización empresariales determinadas, son también quienes más apropiada tienen "la letra" de estas herramientas. Asimismo, las demandas se vuelven a diferenciar de los requerimientos que puedan tener en cuanto a la formación para con las instituciones educativas.

Cuando los empresarios refieren a las políticas de inserción laboral, estas aparecen como herramientas que sirven a sus propósitos de manera parcial, y adquieren un carácter instrumental, lo que no quiere decir que estén de alguna manera vacías de simbolismo o de significado (Shore, 2010). Lo anterior, se refleja en las emisiones principalmente realizadas por empresarios PyMEs (gastronomía, comercio, servicio, produccion como ejemplos de sectores) con experiencia de utilizar de este tipo de políticas: "son buenas" (E12) "son herramientas que sirven, falta mucho más trabajo en la promoción y el trabajo con las entidades, cámaras 
empresariales "publicitan mucho pero no se acercan a las empresas "(E14).

Este tipo de dispositivos entonces, responden de manera parcial a la necesidad de incorporación de nuevos trabajadores para el sector privado, porque aparecen dificultades varias en la implementación o porque no se complementan, según los actores, con la atención a otras cuestiones consideradas problemáticas que también involucran a la acción estatal como la referida a los costos laborales de la contratación.

"son malas (...) no sirven, no están implementadas como corresponde" (E 15).

"No, no la podemos ocupar porque, primero las metodologías de implementación son malas (...) "andan bien (...) Lo que yo sí creo con respecto a ese tema es que, la ayuda que por ahí brindan estos programas no se equiparan a los gastos que uno tiene blanqueando a una persona" (E11).

Se puede inferir, cierta posición reactiva de una parte del empresariado consultado, con respecto a este tipo herramientas. A modo de "usuarios", tienden a demandar determinados servicios a los organismos estatales, similares a los que les solicitarían a consultoras privadas. Lo anterior, dado que, según mencionan, los condicionantes de sus actividades y múltiples funciones que desempeñan en sus organizaciones, les dificulta que asuman posiciones más activas (por ejemplo, acercase a las instituciones del Estado y establecer mayores vínculos).

Por otro lado y contraposición a lo anterior, en el caso de las empresas de Call center, grandes y de capital internacional, la sumatoria de incentivos otorgados es la que determina la continuidad de la actividad:

"es buenísimo (...) porque nosotros no íbamos a venir acá a Chaco, si uno mira no era propicio para el desarrollo nuestro sin una buena alternativa (...) Si el estado quisiera subsidiar a esa 5000 personas les daría un monto mínimo que no les alcanzaría para nada y es como regalar. En cambio, nos da a nosotros y nosotros lo transformamos en trabajo" (E21). La generación de empleo de joven se configura, en casos como este, como una contraprestación al Estado por la maximización de sus beneficios.

Con respecto a la formación para el trabajo, las referencias de los entrevistados en su mayoría, dan cuenta de una construcción positiva del sentido social de la educación y las instituciones educativas públicas. No obstante, se manifiesta cierto desconocimiento de las ofertas estatales en materia de formación profesional, con la salvedad de casos cuyas organizaciones tuvieron/ tienen algún acercamiento a alguna línea o alguna experiencia de articulación propiamente (empresas de desarrollo de software; construcción y actividades relacionadas por ejemplo).

En varias emisiones se señala que las instituciones públicas que forman para el trabajo deben adquirir o reforzar mecanismos de articulación con las organizaciones empresariales para poder responder a las demandas de los mercados de trabajo, tanto las instituciones de nivel medio como las universidades:

"En lo que necesita la calle, en lo que necesita para las actividades que hacen al día a día de la dinámica, la facultad de ingeniería forma grandes ingenieros enciclopedistas” (E23). 
"Tienen que vincularse, están desvinculadas, hay una ruptura, por más que digan que si hay una ruptura, y a la educación le falta aggiornarse, ir a la velocidad de los cambios, va muy atrás" (E21).

Estos reclamos, aparecen más acentuados en empresarios que han seguido formándose en instituciones privadas (están cursando o han obtenido títulos de posgrados, o que se han perfeccionado en escuelas de negocios) o contrariamente no han concluido por diversas razones, sus estudios de nivel superior en la educación pública. Los mismos prevenientes de diferentes sectores de actividad.

Desde estos discursos priman las finalidades de tipo económica para pensar a la formación para el trabajo, se espera su aporte al desarrollo de calificaciones y al desarrollo socio-productivo, respondiendo a nuevas demandas, quedando en segundo plano la atención a cuestiones de inclusión y diversidad, que también son desafíos de esta educación (Sevilla, 2017). Siguiendo estas premisas, se plantea que las ofertas de formación deben estar configuradas desde una lógica fundamentalmente productiva por sobre la lógica educativa y sus principios, ya desde las instituciones de nivel medio, especialmente aludiendo a las escuelas técnicas - que en ideario de muchos empresarios son las instituciones cuya formación y certificación posibilitan una inserción directa al mercado de trabajo-:

"Son necesarias más escuelas técnicas (E15) yo creo que tendría que haber más escuelas técnicas, yo creo que es una formación que te enseña a trabajar desde que salís” (E11).

Asimismo, hay referencias puntuales a la necesidad de incrementar la formación en oficios y la necesidad de tipo de puestos alrededor de estas calificaciones, no obstante, se presenta cierto desconocimiento y valoración sobre instituciones que tradicionalmente atendieron a estas demandas como lo son las ofertas de las escuelas de formación profesional. Como una demanda hacia las instituciones, se remarca que los y las jóvenes deben estar calificados en los saberes específicos requeridos en los mercados de trabajo de los diferentes sectores pero, fundamentalmente, deben adquirir competencias laborales básicas, que según los consultados, muchos jóvenes no poseen, en principio porque son aprendizajes inherentes a los espacios de trabajo:

"Falta mano de obra calificada" (E15).

"Yo creo hay que hacer una intervención en la formación de nuestros jóvenes. Yo creo que tenemos que mirar y discutir como país la educación que estamos brindando, desde la primaria básicamente porque creemos que los jóvenes hoy no salen capacitados, no tienen las herramientas necesarias para empezar a trabajar directamente en una empresa, en un mercado laboral exigente como el nuestro, directamente no las tienen" (E3).

En este sentido, en algunos casos hay cierta apropiación del discurso en torno a la generación, desarrollo y evaluación de competencias laborales, debido al acercamiento a perspectivas teóricas en relación a la labor gerencial, marketing y relacionadas. Aparecen también referencias a las habilidades "blandas" como habilidades sociales o emocionales que el sujeto debe 
poseer, con un énfasis puesto en lo individual.

“preparan para la empresa del pasado o la del futuro?” (E21).

"el que se postula tiene que tener conocimiento de lo que esperan las empresas, enfocar a las personas en cuanto a las capacidades y las competencias que se esperan” (E15).

Gran parte de los actores consultados promueve acciones de capacitación en sus empresas, mayormente de forma interna, sobre temáticas generales (como higiene y seguridad) y otras de tipo técnico, más específicas y puntuales para algunos tipos de tareas y puestos (desde oratoria, instancias de coaching entre otras) la capacitación se orienta fundamentalmente como "un factor importante para que todos los colaboradores y responsables de la empresa aporten lo mejor para su productividad. La capacitación es un proceso constante que busca la eficiencia y con ella alcanzar niveles elevados de productividad" (Bermúdez Castillo, 2015, p.7). Como mencionamos precedentemente, muy pocas articulan con instituciones educativas para estas instancias. En varios casos, se articula con entidades empresariales que generan una agenda eventos con fines formativos, primordialmente empresarios PyMEs con responsabilidades dentro de las organizaciones mencionadas.

Cabe destacar que algunos empresarios asumen que sus organizaciones se configuran como "empresa escuela" (E12), como receptora y generadora del primer empleo, principalmente, actores del sector de la gastronomía, software y call centers todos menores de 40 años. En estos casos, se resalta que en la selección e incorporación de jóvenes trabajadores, la experiencia como requisito no cobra tanta importancia. Sí, en cambio las predisposiciones y competencias que demuestren los postulantes hacia el puesto. No obstante, también aparecen referencias a la formación como un "costo" y en relación a los jóvenes, un costo que el empresario no siempre recupera dada la volatilidad y falta de compromiso de los mismos en los puestos, esto principalmente resaltado por empresarios de sectores de produccion de alimentos, entre 35 y 50 años.

En síntesis, los vínculos educación y trabajo constituyen terreno de batalla sobre las diversas concepciones referida a la educación, el trabajo y la sociedad, la disputa es fundamentalmente por las finalidades que debe tener la formación para el trabajo, que lógicas debe priorizar y a que sectores debe generar mayores beneficios.

\section{REFLEXIONES FINALES}

En este trabajo intentamos identificar y describir algunos de los sentidos construidos por los empresarios del Gran Resistencia, sobre los jóvenes y las políticas públicas de formación e inserción laboral.

A modo de reflexión final podemos señalar que, no hay una orientación o tipo de discurso único dentro del empresariado local sobre este grupo y estas acciones estales, sino que más 
bien aparecen sentidos diversificados, derivados justamente de la heterogeneidad de perfiles, trayectorias y posicionamientos de estos actores.

Con respecto a la formación para el trabajo, prima en los discursos una lógica de tipo económica en cuanto a sus finalidades, donde la misma se presenta como una herramienta fundamental para el mejoramiento de las situaciones de las empresas privadas y el desarrollo productivo de la provincia (Sevilla 2017). No obstante, se manifiesta también cierto desconocimiento de las ofertas estatales en materia de formación profesional. Por otro lado, si bien desde las concepciones que sostienen los diseños de los programas o dispositivos estatales se piensa al actor empresarial con un rol de coresponsabilidad en la implementación de estas acciones, algunos de los planteos y demandas que los entrevistados realizan, permiten ubicarlos más bien en un rol diferente, como otros "usuarios" o “clientes” más del Estado y sus políticas.

En cuanto a las referencias sobre las juventudes tampoco hay un discurso unificado, en las emisiones se presentan algunas referencias positivas por un lado y negativas por otro, las últimas con una fuerte carga semántica que permite inferir ciertas visiones estereotipadas por parte de algunos actores. Las visiones estereotipadas sobre las juventudes, responden a la persistencia de una mirada adultocéntrica que, en parte desconoce, ciertas transformaciones contemporáneas en la condición juvenil. El peligro de los estereotipos es que se convierten en condicionantes primero desde lo simbólico y luego derivan en las prácticas, en lo material (y en estos casos se restringen horizontes de posibilidad en el desarrollo de las trayectorias de algunos jóvenes).

Pensar en los procesos de inserción laboral juvenil como una construcción social requiere, por un lado, seguir explorando los modos en que cada uno de estos actores participa de los mismos e indagando los sentidos que construyen pero, por otro lado, la habilitación de espacios de diálogo, de intercambio, para reconocer estos "desencuentros" de sentidos y proyectar estrategias para mejorarlos.

\section{REFERENCIAS BIBLIOGRÁFICAS}

Alonso, O. (2004). La lógica de los actores y el desarrollo local. Revista Pilquen, (6), 1-12. Recuperado en 04 de octubre de 2018, de http://www.scielo.org.ar/scielo.php?script=sci arttext\&pid=S1851-31232004000100004\&lng=es\&tlng=es

Barbetti, P., Pozzer, J., Castillo, S., Cardozo, D. (2017). Las miradas del empresariado de Chaco y Corrientes sobre las políticas de empleo y los jóvenes. En Beretta D [et al.] (Comp) Estudios sobre juventudes en Argentina V: juventudes en disputa: permeabilidad y tensiones entre investigaciones y políticas. Recuperado de http://rephip.unr.edu.ar/xmlui/bitstream/handle/2133/9308/Libro\%2oRenija\%202017.pdf?sequence=3\&isAllowed=y 
Bueno Campos, E. (2007). Organización de Empresas: Estructura, Procesos y Modelos. España: Ed. Pirámide.

Bermúdez Carrillo, L.A. (2015). Capacitación: una herramienta de fortalecimiento de las pymes. InterSedes: Revista de las Sedes Regionales, 16(33),1-25.

Coseriu. (1981). Lecciones de lingüística general. España: Gredos.

Cuarta, P. (2008). De la ética del trabajo a la estética del consumo. AD-MINISTER, (12), 140-148. Medellín: Universidad EAFIT.

Chorny, V. (2016). El discurso de los funcionarios sobre los jóvenes y las políticas públicas. Representaciones encontradas entre la Ciudad de Buenos Aires y la Provincia de Santa Fe. Argumentos: Revista de crítica social, (18), 207-230.

De Ibarrola, M. (2016). Claroscuros en las relaciones entre la escolaridad y el trabajo. Configuraciones y límites. Revista Páginas de Educación, 9(2), https://doi.org/10.22235/pe.v9i2.1293

Dossi, M. \& Lissin, L. (2011). La acción empresarial organizada: propuesta de abordaje para el estudio del empresariado. Revista Mexicana de Sociología, 73(3), 415-443.

Dubar, C. (2001). La construction sociale de l'insertion professionnelle. Education et Sociétés, (7), 23-36. Traducción al español del Programa de Estudios sobre Juventud, Educación y Trabajo, PREJET.

Foio, M. y Pérez Rubio, A. (2009). El proceso de micro-regionalización como estrategia del desarrollo local: un estudio en la provincia del Chaco. Revista de Estudios Regionales y Mercado de Trabajo, (5), 265-279.

Gonzalez, R. (2011) La incorporación de la Generación Y al mercado laboral. El caso de una Entidad Financiera de la ciudad de Resistencia. Palermo Business Review (5), 67-93.

Jacinto, C. (2019). La formación para el trabajo como sistema. Curso Virtual: La formación para el trabajo de jóvenes. Herramientas teóricas y metodológicas, Clase 2, PREJET, Ides-CIS-Conicet.

Jacinto, C. \& Millenaar, V. (2012). Los nuevos saberes para la inserción laboral. Formación para el trabajo con jóvenes vulnerables en Argentina. Revista Mexicana de Investigación Educativa, $17(52), 141-166$. 
Jacinto, C. (2008). Los dispositivos recientes de empleo juvenil: institucionalidades, articulaciones con la educación formal y socialización laboral. Revista de Trabajo, 4(6). Buenos Aires: MTEySS.

Margulis, M. \& Urresti, M. (1998). La construcción social de la condición de juventud. M.C. Laverde Toscazo y otros (Eds). Viviendo a toda. Jóvenes, territorios culturales y nuevas sensibilidades (3-21). Santa Fe de Bogotá, Colombia: Siglo del Hombre Editores.

Neffa, J. C. (2017). El contexto socio económico argentino actual. Cuadernos del CENDES. (95). 189-205.

Palazzo, M. G. (2014). Un recorrido por categorías y representaciones sobre juventud en las Ciencias Sociales. Revista de comunicación Vivat Academia, (129), 119-147.

Piris, C. \& Glibota Landriel, V. M. L. (2015). La empresa en el código civil y comercial argentino. Revista de la Facultad de Ciencias Económicas, (14), 126-145. http://dx.doi.org/10.30972/ rfce.014369

Pozzer, J. (2018). Prácticas en lugares de trabajo en los programas de empleo juvenil: experiencias, cambios y continuidades en su implementación. Revista de la Facultad de Ciencias Económicas, 21(2), 79-99. http://dx.doi.org/10.30972/rfce.0213729

Schorr, M. (coord.). (2016). La industria chaqueña en el siglo XXI. Un análisis de la evolución de la industria chaqueña desde los 9o" hasta la actualidad. Resistencia: Escuela de Gobierno.

Valencia, M. (2005). Las competencias laborales: ¿La estrategia laboral para la competitividad de las organizaciones?. Estudios gerenciales, (96), 31-55.

Vera, A. (2009). Los Jóvenes y la Formación para el Trabajo en América Latina. Documento de Trabajo, 25. Buenos Aires: CIPPEC.

Verdier, E. \& Vultur, M. (2018). La inserción laboral de los jóvenes: un concepto histórico, ambiguo y societal. Cuestiones de Sociología, (19), eo67. https://doi.org/10.24215/23468904e067 


\section{CURRICULUM VITAE}

\section{Daiana Giannina I. Cardozo}

Licenciada en Ciencias de la Educación por la Facultad de Humanidades, Universidad Nacional del Nordeste. Maestranda en Ciencias Sociales e Humanidades, Universidad Nacional de Quilmes. Actualmente becaria de investigación por la Secretaria General de Ciencia y Técnica, UNNE. cardozodaiana7o@gmail.com

\section{Pablo Andrés Barbetti}

Licenciado en Relaciones Laborales y Magister en Desarrollo Social, Universidad Nacional del Nordeste. Doctorando en Ciencias Humanas y Sociales, Universidad Nacional del Nordeste. Docente-Investigador de la UNNE. pablobarbetti@hotmail.com 